Original article

\title{
EFFECT OF WORKPLACE SPIRITUALITY ON PROJECT TEAM CREATIVITY WITH MEDIATING ROLE OF PROJECT TEAM PRUDENCE AND PROJECT TEAM VIRTUE
}

\author{
Hasan Ali $^{1}$, Ubaid ur Rehman ${ }^{2}$
}

\author{
${ }^{1,2}$ Shaheed Zulfikar Ali Bhutto \\ Institute of Science and \\ Technology (SZABIST), \\ Islamabad, Pakistan
}

Received: 2 October 2020 Revised: 20 October 2020 Accepted: 15 January 2021

\begin{abstract}
Purpose of this research is to investigate the impact of workplace spirituality on project team creativity and the mediating role of project team prudence $\&$ project team virtue between workplace spirituality and project team creativity. The data for this study has been collected from Telecommunication Services Provider Industry of Pakistan. We tested the effect of workplace spirituality on project team creativity and further examined the mediating effects of project team prudence \& project team virtue between workplace spirituality and project team creativity. Results indicated that workplace spirituality has a moderate correlation with project team creativity and there is partial mediation in our model via only one mediator project team prudence. Future researchers may opt to conduct the research by including additional moderating variables, examining underlying factors of workplace spirituality and establish their relationship with project team creativity both at higher and medium level of project team management.
\end{abstract}

Keywords: Project team creativity, project team prudence, project team virtue, telecom industry, workplace spirituality.

\section{INTRODUCTION}

Innovation and creativity have become integral part for any organization to survive and succeed in today's era of rapidly changing business environment, globalization, and technological advancements. Researchers recommended that organizations are required to be more adaptable to achieve more success (Sherehiy, et al., 2007) for this a large number of organizations have emphasized on promoting workplace spirituality an environment where employees find meaning or purpose at work, feels passionate, and a match between the requirements of work and values, beliefs and behaviors. Since creativity is difficult to achieve by individuality (Hoegl, et al., 2004) it is necessary to have teams members with empathy, skills, urge to share knowledge among themselves, help eachother in finding innovative solutions to problems etc. The concept of work life spirituality is based on the ethics, trust, motivation, work life balance, and respect among project team members (Daniel, 2010). Spirituality at workplace is driven by multiple factors: internal (human), external (organizational), integrated (human / organizational), and once these factors are unified creativity of the project team shows a substantial progress (Marques, et al., 2005). In available literature on workplace spirituality influence of workplace spirituality on project team creativity still remain in grey area and is not directly addressed in the most focused and concerted way.

Large number of projects are failing due to lack of creativity and innovation. To be more innovative and creative, organizations usually 
rely on teams and their skillset (individual and collectively). Creating innovative products is a complex process and require ample knowledge of different domains and it often exceeds the capacity of an individual project team member (Hoegl, et al., 2004). An innovative and creative project team comprises of members who have team prudence, team virtue, attitude to help each other in difficult circumstances throughout the project lifecycle. This outlines the underlying motive to examine and explore the relationship between project team creativity and workplace spirituality. The present study adds value to theory and practice in multiple ways and will be a value addition in literature for helping policy makers in organizations to adopt workplace spirituality for increasing team creativity. It also offers a refined understanding of workplace spirituality in organizations by highlighting its positive influence on team prudence and team virtue.

\section{THEORETICAL BACKGROUND}

Workplace spirituality is not about theology of one's religious beliefs \& practices neither it is about God nor Religion. Workplace spirituality advocates the concept of a culture that every employees have both a mind and a spirit to find meaning and purposes in their work and to experience a real sense of trust and personal connection with coworkers. The workplace spirituality can be segregated in two categories individual and organizational. Individual spirituality is all about understanding our power and to understand the process involved in exchanging our energy with others (Moitreyee, \& Chandra, 2015) whereas organizational spirituality includes creating a culture in which an employee loves their jobs and their personal values are linked with organizations vision and mission.

Prudence is the ability to handle / manage practical problems using reasons, skills, expert judgment and deep understanding of the issue at hand. Prudence is not a singular attribute it is a blend of team networking, team diversity and team experience (Ryan, \& O'connor, 2009). Team prudence discourage the concept of "I" and promotes to become "we" and urge project team members to leave their selfcentered behaviors and adopt work collaboration with others to support all team members in achieving project goals efficiently (Eikeland, 2006). Šmite, Moe, Šāblis and Wohlin (2017) explored that by integrating knowledge and experience of a project team, prudency can be achieved which is critical to overcome the project issues. (Pinjani, \& Palvia, 2013) explained that having project team members with diverse experience creates more prudent environment as their experience of different scenarios and environment helps in achieving team creativity and making right decisions.

Wisdom nexus, honesty, courage, compassion, generosity, fidelity, integrity, fairness, selfcontrol are all examples of virtues (Miller, 2018; Proust, 2014; Stanley, 2005). Virtue is the quality of being morally good or showing high standards of moral. To benefit crossfunctional project teams and enabling knowledge diversity virtue-ethical behaviors are mandatory (Zhang, \& Guo, 2019). Team virtue also nullify the factor of social categorizations of project team members (Bright, Winn, \& Kanov, 2014) in this manner project team members shows more empathy toward eachother. Project problems are resolved by project team members by utilizing their professional experience $\&$ knowledge in a collaborative manner (Nielsen, et al., 2006).

Project Team Creativity is the creation of new and helpful ideas, services, procedures, products, and processes. Researchers have differentiated between creativity \& innovation. Innovation involves two stages firstly, innovation is the generation of new ideas and secondly, the implementation of the idea. Creativity lies at the first stage of innovation. Team creativity is generalized as ideas or solutions that are novel and useful for any organization (Amabile, 2012) which are motivated \& supported by different organizational processes (Beersma, \& De Dreu, 2005; Berg, 2014; Miron-Spektor, \& Beenen, 2015; Mueller, Melwani, \& Goncalo, 2012). Since different avenues of creativity e.g. increased collaboration, effective communications, stakeholder (Sirisomboonsuk, et al., 2018), constitute the project team creativity process, Process philosophy theory (Styhre, 2002) relate these avenues to this empirical study. Being consistent with the extended literature, we put 
forward the view that the project team creativity is enhanced by virtue and prudent practices (Kupperman, 2009).

\section{WORKPLACE SPIRITUALITY AND PROJECT TEAM CREATIVITY}

Modern organizations are incorporating spiritually oriented culture for improving employees' creativity and performance. Spirituality at workplace has the potential to light up the creative power of the employees with awareness \& intuition leading to creativity (Freer, \& Robertson, 2020). Spiritualized culture enhances teamwork and employee commitment to the organization it also contributes to develop a more purposeful and compelling organizational vision with increased innovation. (Badrinarayanan, \& Madhavaram, 2008) mentioned that all those organizations, which encourage workplace spirituality, energize their employees emotionally and motivate them to be more creative, productive and successful.

Workplace spirituality was initially described as employees seeking connectedness in their working environment while exploring their inner selves (Ashmos, \& Duchon, 2000). Some researchers extended this concept of Workplace spirituality and claimed that workplace spirituality is not only interconnectedness of ourselves but also with the environment and ultimately with all things in the universe (Mitroff, 2003). Though workplace spirituality is under spotlight since last 02 decades and ample literature is available but the effect of workplace spirituality on project team creativity was not directly addressed in the most focused manner. A notable exception is have empirically examined the relationship between spirituality and team creativity at the team level (Harrison, 2020) but researchers need to explore the avenues to make this claim valid. In this research, workplace spirituality provides an overarching framework, and by incorporating decoupled team prudence (Dalal, \& Pauleen, 2019) and team virtue (Wang, et al., 2017) practices in project teams.
Hypothesis-1: Workplace Spirituality is positively and significantly associated with Project Team Creativity.

\section{MEDIATING ROLE OF PROJECT TEAM PRUDENCE AND PROJECT TEAM VIRTUE BETWEEN WORKPLACE SPIRITUALITY AND PROJECT TEAM CREATIVITY}

Being coherent with the arguments found in the previous available literature (Flyvbjerg, 2004) team virtue $\&$ prudence work side by side (a co-variate) during course of project and their collaboration creates harmony in the relationship between the workplace spirituality and project team creativity. Project team prudence is positively related to project team creativity by supporting the appropriate solutions about project related issues during the constructive \& problem-solving meetings / discussions / conversations. Experienced project team members understand the importance of the project in organizational vison and by using their diverse experience of resolving project related issues a mutual team reasoning \& intuition is established. It also advocated that the coherent and coordinated actions are essential for creative solutions to project problems while improving the interpersonal relationships and information sharing. The fact is to be understood that the routes to team creativity are still being explored and there is a lot that we need to know for fully understanding the concept of creativity. Different studies identified and recommended certain characteristics to achieve the compatibility and enhance the project creativity process. In modern project management creative approach can do wonders with help of series of brainstorming sessions, review meetings and development of more processes to support creativity.

Hypothesis-2: Project Team Prudence mediates the relationship between Workplace Spirituality and Project Team Creativity.

Hypothesis-3: Project Team Virtue mediates the relationship between Workplace Spirituality and Project Team Creativity 


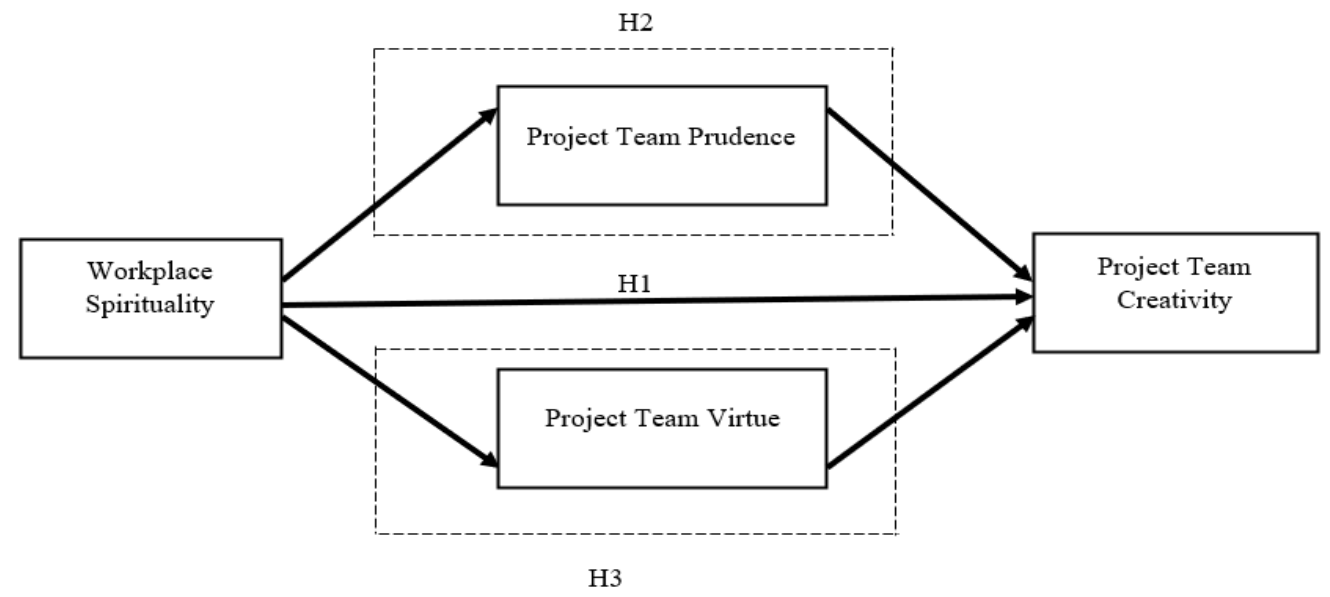

Figure 1: Theoretical Model underlying empirical research

\section{RESEARCH DESIGN AND DATA COLLECTION}

Data collection for this cross-sectional quantitative research study has been conducted through "Questionnaire" technique. The population selected was Telecommunication Services Provider Industry of Pakistan. Questionnaire was developed on the basis of previously established questions available in literature. The survey questionnaire contained two (02) sections, including demographic information while the other part comprised of questions related to variables under investigation. We have used three (04) variables naming Workplace Spirituality (WPS), Project Team Prudence (PTP), Project Team Virtue (PTV) and Project Team Creativity (PTC) these variables were measured using 5-point Likert scale that ranges from 01 (strongly agree) to 05 (strongly disagree). Eighteen (18) questions for variable WPS has been adopted from research work of (Kinjerski, \& Skrypnek, 2006) Five (05) questions related to PTP and Seven (07) questions related to PTV adopted from research work of (Akgün, 2020) and ten (10) Questions for PTC were adopted from research work of (Wang, \& Wang, 2012). The study was performed from February to May 2020.s Initially fifty (50) questionnaires were distributed with 41 returned out of which 38 were valid questionnaires in second phase of data collection due to COVID-19 pandemic it was not possible to collect the response through visits and meetings. Therefore, researcher utilized 'SurveyMonkey' and 'Google Forms' to deliver the questionnaire and 175 responses were recorded via internet which makes the total to 213 responses.

\section{NORMALITY AND RELIABILITY OF DATA}

Detailed analysis of the collected survey responses was performed via Statistical Package for the Social Sciences (SPSS). The data was confirmed to have no missing values which might prevent accurate analysis. The results of Skewness and Kurtosis with respect to each variable independently shows that all the values are well within range. The reliability of every variable scale used was tested through Cronbach's Alpha ( $\alpha$ ) calculation and all the values of Cronbach's $\alpha$ were greater than 0.7, which confirms that the questionnaire has a very good reliability. Data preparation for factor analysis was done using Kaiser-MeyerOlkin (KMO) and Bartlett's tests which indicates that sample is adequate factor loading analysis is suitable for the collected data.

\section{RESEARCH RESULTS}

Research survey questionnaire also includes demographic scale such as the Gender, Age, Qualifications and Experience of the respondents. $66 \%$ respondent were male, $72 \%$ respondent holding Project Management Experience, $79 \%$ respondent have experience between 8 to 11 years, and 95\% respondent working on Projects. Descriptive analysis shows that variables distributions proved to be normal, Skewness and Kurtosis with respect to each variable independently shows that the values are well within range. In our factor analysis any value less than 0.70 have been be 
dropped in order to have acceptable results overall. Therefore, values against WPS1, WPS2, WPS7, WPS9, WPS10, WPS16, PTP4, and PTC5 were dropped in further analysis.

\section{VARIABLE RELATIONSHIP}

Correlation tells the intensity of the relationship between all the variables under discussion Pearson Correlation analysis was conducted for this research work which shows that the relationship between WPS and PTP is +0.667 which is strong and significant, relationship between WPS and PTV is +0.603 which is strong and significant, relationship between WPS and PTC is +0.591 which is strong and significant, relationship between PTP and PTV is +0.685 which is strong and significant, relationship between PTP and PTC +0.576 which is moderate and significant and relationship between PTV and PTC is +0.509 which is moderate and significant.

Table 1: Summary of correlations between Variables

\begin{tabular}{cccc}
\hline Relationship & Value & Significance & Intensit0079 \\
\hline PTP \& WPS & +0.667 & 0.000 & Strong, Significant, Positive Relationship \\
PTV \& WPS & +0.603 & 0.000 & Strong, Significant, Positive Relationship \\
PTV \& PTP & +0.685 & 0.000 & Strong, Significant, Positive Relationship \\
PTC \&WPS & +0.591 & 0.000 & Moderate, Significant, Positive Relationship \\
PTC \& PTP & +0.576 & 0.000 & Moderate, Significant, Positive Relationship \\
PTC \& PTV & +0.509 & 0.000 & Moderate, Significant, Positive Relationship \\
\hline
\end{tabular}

\section{REGRESSION MODELS}

In our analysis Adjusted R Square value is 0.346 which shows that independent variable Workplace Spirituality (WPS) will bring $34.6 \%$ change in dependent variable i.e.
Project Team Creativity (PTC). To calculate parallel mediation effect and conditional process analysis we used Model Number-4 of Preacher and Hayes with bootstrap ( $\mathrm{n}=1000,95 \%$ CI $)$ using SPSS.

Table 2: Regression Testing

\begin{tabular}{lccccc}
\hline Path & R-Sq. & Adjusted R Sq. & Beta Value & T Value & P Value \\
\hline WPS $\rightarrow$ PTC & 0.349 & 0.346 & 0.591 & 10.637 & .000 \\
\hline
\end{tabular}

In our model where we have WPS, PTP, PTV are serving as predictors of PTC. Direct effect of WPS on PTC after controlling for PTP and PTV is still statistically significant as p-value < 0.05 Relationship between WPS and PTC and relationship between PTP and PTC are also statistically significant. Whereas, relationship between PTV and PTC is not statistically significant as p-value $>0.05$.

Table 3: Summary of Model

\begin{tabular}{lllllll}
\hline & coeff & se & t & p Value & LLCI & ULCI \\
\hline constant & 0.621 & 1.442 & 0.431 & 0.667 & -2.222 & 3.464 \\
PTP & 0.531 & 0.161 & 3.305 & 0.001 & 0.214 & 0.847 \\
PTV & 0.178 & 0.110 & 1.610 & 0.108 & -0.039 & 0.395 \\
WPS & 0.385 & 0.083 & 4.618 & 0.000 & 0.220 & 0.550 \\
\hline
\end{tabular}

While further analyzing indirect effects of WPS on PTC we observed that 0 doesn't fall between Upper (0.371) and Lower (0.057) limit of Confidence Interval of mediation route of WPS to PTC via PTP and this route is statistically significant. Whereas, 0 does fall between Upper (0.228) and Lower (-0.033) limit of Confidence Interval of mediation route of WPS to PTC via PTV also this route is not statistically significant. Hence we can conclude that there is partial mediation in our model via mediator PTP. 
Table 4: Indirect Effect of $X$ on $Y$

\begin{tabular}{ccccc}
\hline & Effect & Boot SE & Boot LLCI & Boot ULCI \\
\hline Total & 0.284 & 0.104 & 0.068 & 0.485 \\
PTP & 0.201 & 0.081 & 0.057 & 0.371 \\
PTV & 0.083 & 0.066 & -0.033 & 0.228 \\
\hline
\end{tabular}

\section{DISCUSSION}

The relationship between workplace spirituality and project team creativity is a noteworthy issue. Reasons for this are the profusion of the concept of workplace spirituality, ambiguity of the concept of spirituality in the context of team creativity and the variety of ways the two variables may be related with each other. While the theories that support workplace spirituality are attractive and logical, to date, what has been missing is empirical validation. Spirituality helps in exploring the new avenues ahead of the normal thinking, leading to increased creativity. There is additional empirical evidence resulted out of this study to support the fact that organizations and enterprises need to advocate workplace spirituality to achieve higher levels of team creativity.

This study described whether and how workplace spirituality effects the project team creativity through a comprehensive and empirical analysis. Our research work offer limited support for previous research work by (Buckler, \& Zien, 1996; Harrison, 2020) in which the relationship between spirituality \& innovation and collective engagement of workplace spirituality in creative tasks was investigated. There are many areas of office life in which spiritual intelligence can be applied and benefits can be obtained to the maximum by nourishing the factors impacting the balance between work life and spiritual beliefs. We conclude that workplace spirituality plays a significant role in establishing a strong, well understood and positive organizational culture which ultimately raise level of organizational productivity. An insignificant parallel mediating effects of project team prudence and project team virtue was investigated between workplace spirituality and project team creativity.

\section{CONCLUSION}

Aim of this study was to explore the direct effect of workplace spirituality and project team creativity and what are the indirect effect of workplace spirituality and project team creativity via project team prudence and project team virtue. There was positive relationship witnessed between workplace spirituality and project team creativity. On the other hand, one of the proposed mediators Project Team Virtue was not found to mediate the relationship between workplace spirituality and project team creativity. In regression analysis explained in Table 9 and 10 we can conclude that Workplace Spirituality (WPS) is statistically related to both mediators within the model. The value of coefficients is also positive (+ve) for both mediators Project Team Prudence and Project Team Virtue i.e. 0.38 and 0.467 respectively here it is interesting to note that regression analysis showed statistical significance but low values for percentage of variance explained i.e. R2-value.

Concept of spirituality in the workplace is been a hot topic among corporate, academicians and researchers. Workplace spirituality has many benefits which are yet to be explored and sooner or later workplace spirituality (WPS) will become the fundamental and most important factor of every business for achieving and maintaining success. Different research work has shown that organizations that advocates the concept of workplace spirituality (WPS) and encourage their employees in adopting the culture of spirituality at workplace are better in performance and creativity as compared the other organization of same scale (Wilson, 2017).

Spirituality in workplace enables employees to interact more deeply in their work while having a relationship with others team members. Despite of the fact that organization is public or private, Organization's should enhance 
culture of spirituality at workplace on a regular basis to increase employee's creativity (Marques, 2005).

\section{THEORETICAL AND PRACTICAL IMPLICATIONS}

This study has enabled us to understand the concept that how workplace spirituality, project team prudence and project team virtue effects project team creativity via their relationship as described in theoretical framework. We have examined the linking of workplace spirituality and project team creativity through Telecommunication Professionals sample. First, workplace spirituality has been studied with regards to the project team creativity perspective and then addition of proposed mediators project team prudence and project team virtue. This study is addition in literature of workplace spirituality and provides a guideline to the policy makers in organizations that are striving to maximize project team creativity.

We have also found that the theoretical model got the practical implications, both for the managers and organization involved in project. This study can be referred to the organizations that are striving to maximize project team creativity and are not very clear about adopting workplace spirituality.

\section{LIMITATION AND FUTURE WORK}

Although our findings offered some intriguing perspectives on workplace spirituality and its impact on project team creativity, there were also some limitations to the study that need to be acknowledged. First, 'non-response' errors in survey questionnaire i.e. the participants fail to understand and respond to particular questions in its true essence and 'response error' survey questionnaire i.e. where the participant does not give an accurate response or gives an incomplete response (Cooper, \& Schindler, 2001). Secondly, limitation of this research was an examination of the impact of the different organizational cultural behaviors (shared values, beliefs, ideologies, principles, attitudes and the set of assumptions) on the relationship between workplace spirituality and project team creativity. It is observed that team prudence requires interactive skills at individual level i.e. team members to be more involved with eachother in problem solving and knowledge sharing and its effect on virtual and global project teams can be examined. Also, most of the published research work (Dalal, \& Pauleen, 2019) have mainly focused on documented lesson learned in specific scenarios about effects of team prudence on team creativity. In this study, we briefly examined effect of project team virtue on project team creativity. For future research on how project team members' individual traits of virtue, morality, integrity, righteousness etc. collectively effects project team creativity and performance should be critically investigated. Most importantly factors to convert individual virtue into collective team virtue are also not explored from project team creativity perspective. Although workplace spirituality has been adopted in organizations for several years now, to our knowledge, this research is one of the first empirical studies on workplace spirituality and project team creativity in Telecommunication sector of Pakistan. Future researchers should examine underlying factors of workplace spirituality and establish their relationship with project team creativity by multiple perspectives (efficiency, results, stakeholder satisfaction etc.) both at higher and medium level of project team management.

\section{REFERENCES}

Akgün, A. E. (2020). Team wisdom in software development projects and its impact on project performance. International Journal of Information Management, 50, pp. 228-243.

Amabile, T. M. (2012). Componential theory of creativity. Harvard Business School, 12(96), pp. 1-10.

Ashmos, D. P., \& Duchon, D. (2000). Spirituality at work: A conceptualization and measure. Journal of management inquiry, 9(2), pp. 134-145.

Badrinarayanan, V., \& Madhavaram, S. (2008). Workplace spirituality and the selling organization: A conceptual framework and research propositions. Journal of Personal Selling \& Sales Management, 28(4), pp. 421-434.

Beersma, B., \& De Dreu, C. K. (2005). Conflict's consequences: Effects of social 
motives on postnegotiation creative and convergent group functioning and performance. Journal of personality and social psychology, 89(3), 358.

Berg, J. M. (2014). The primal mark: How the beginning shapes the end in the development of creative ideas. Organizational Behavior and Human Decision Processes, 125(1), pp. 1-17.

Bright, D. S., Winn, B. A., \& Kanov, J. (2014). Reconsidering virtue: Differences of perspective in virtue ethics and the positive social sciences. Journal of business ethics, 119(4), pp. 445-460.

Buckler, S. A., \& Zien, K. A. (1996). The spirituality of innovation: learning from stories. Journal of Product Innovation Management: An international publication of the product development \& management association, 13(5), pp. 391405.

Cooper, D., \& Schindler, P. (2001). Business Research Methods Boston: McGrawHiIIlnl'in.

Dalal, N., \& Pauleen, D. J. (2019). The wisdom nexus: Guiding information systems research, practice, and education. Information Systems Journal, 29(1), pp. 224-244.

Daniel, J. L. (2010). The effect of workplace spirituality on team effectiveness. Journal of Management Development.

Eikeland, O. (2006). Phronesis, Aristotle, and action research. International Journal of Action Research, 2(1), pp. 5-53.

Flyvbjerg, B. (2004). Phronetic planning research: Theoretical and methodological reflections. Planning Theory \& Practice, 5(3), pp. 283-306.

Freer, A. S., \& Robertson, P. J. (2020). Organizational spiritual maturity: a goal of positive leaders and direction for change. In New Horizons in Positive Leadership and Change (pp. 103-125): Springer.

Harrison, J. (2020). Aspects of Spirituality. Inprint.

Hoegl, M., Weinkauf, K., \& Gemuenden, H. G. (2004). Interteam coordination, project commitment, and teamwork in multiteam R\&D projects: A longitudinal study. Organization science, 15(1), pp. 38-55.
Kinjerski, V., \& Skrypnek, B. J. (2006). MEASURING THE INTANGIBLE: DEVELOPMENT OF THE SPIRIT AT WORK SCALE. Paper presented at the Academy of management proceedings.

Kupperman, J. J. (2009). Virtue in virtue ethics. The Journal of Ethics, 13(2-3), pp. 243-255.

Marques, J. (2005). Socializing a capitalistic world: Redefining the bottom line. Journal of American Academy of Business, 7(1), 283.

Marques, J., Dhiman, S., \& King, R. (2005). Spirituality in the workplace: Developing an integral model and a comprehensive definition. Journal of American Academy of Business, 7(1), pp. 81-91.

Miller, S. (2018). Joint epistemic action: Some applications. Journal of Applied Philosophy, 35(2), pp. 300-318.

Miron-Spektor, E., \& Beenen, G. (2015). Motivating creativity: The effects of sequential and simultaneous learning and performance achievement goals on product novelty and usefulness. Organizational Behavior and Human Decision Processes, 127, pp. 53-65.

Mitroff, I. I. (2003). Do not promote religion under the guise of spirituality. Organization, 10(2), pp. 375-382.

Moitreyee, P., \& Chandra, S. (2015). Workplace spirituality-The essence of modern business organizations. Abhinav National Monthly Refereed Journal of Research in Commerce \& Management, 4(3), pp. 50-56.

Mueller, J. S., Melwani, S., \& Goncalo, J. A. (2012). The bias against creativity: Why people desire but reject creative ideas. Psychological science, 23(1), pp. 13-17.

Nielsen, T. M., Edmondson, A. C., \& Sundstrom, E. (2006). Team wisdom: Definition, dynamics, and applications. Dynamics, and Applications (June 2006).

Pinjani, P., \& Palvia, P. (2013). Trust and knowledge sharing in diverse global virtual teams. Information \& Management, 50(4), pp. 144-153.

Proust, J. (2014). Epistemic action, extended knowledge, and metacognition. Philosophical Issues, 24(1), pp. 364-392.

Ryan, S., \& O'connor, R. V. (2009). 
Development of a team measure for tacit knowledge in software development teams. Journal of Systems and Software, 82(2), pp. 229-240.

Sherehiy, B., Karwowski, W., \& Layer, J. K. (2007). A review of enterprise agility: Concepts, frameworks, and attributes. International Journal of industrial ergonomics, 37(5), pp. 445-460.

Sirisomboonsuk, P., Gu, V. C., Cao, R. Q., \& Burns, J. R. (2018). Relationships between project governance and information technology governance and their impact on project performance. International journal of project management, 36(2), pp. 287-300.

Šmite, D., Moe, N. B., Šāblis, A., \& Wohlin, C. (2017). Software teams and their knowledge networks in large-scale software development. Information and Software Technology, 86, pp. 71-86.

Stanley, J. (2005). Knowledge and practical interests: Clarendon Press.

Styhre, A. (2002). How process philosophy can contribute to strategic management. Systems Research and Behavioral
Science, 19(6), pp. 577-587.

Wang, J., Keil, M., Oh, L.-b., \& Shen, Y. (2017). Impacts of organizational commitment, interpersonal closeness, and Confucian ethics on willingness to report bad news in software projects. Journal of Systems and Software, 125, pp. 220-233.

Wang, Z., \& Wang, N. (2012). Knowledge sharing, innovation and firm performance. Expert systems with applications, 39(10), pp. 8899-8908.

Wilson, D. (2017). Maintaining 'respect for spirituality'in a secular work environment: a Biographical account of the career-life journey of a black female practitioner of declared faith. In Managing VUCA Through Integrative Self-Management (pp. 81-106): Springer.

Zhang, L., \& Guo, H. (2019). Enabling knowledge diversity to benefit crossfunctional project teams: Joint roles of knowledge leadership and transactive memory system. Information \& Management, 56(8), pp. 103-156. 